\title{
Democracia y política: notas para repensar al pueblo en clave política
}

\author{
Gabriel Moreno Montoya \\ Universidad Nacional Mayor de San Marcos
}

\section{Resumen}

En el presente artículo se reflexionará sobre las estrategias políticas de lo popular y su relación con la democracia. A partir de un diálogo crítico entre Ernesto Laclau y Jacques Rancière, se proponen dos estrategias que permitan comprender la constitución de lo popular como sujeto político. En la primera estrategia ranceriana, tanto la reestructuración del espacio público como la reapropiación de ciertos dispositivos estatales instituyen al pueblo como actor político. Sin embargo, esta reapropiación no significa la inclusión del sujeto popular a las dinámicas estatales, sino un ensanchamiento del sentido de estos dispositivos a partir de la emergencia de los sujetos políticos. En la segunda estrategia laclausiana populista, la articulación de múltiples demandas a partir de los significantes vacíos y del antagonismo político sugiere la posibilidad de pensar una amplia reconfiguración de las complejas dimensiones de lo estatal, sin que esto suponga una completa reducción de lo popular a lo estatal. Esta última estrategia abre también la posibilidad de pensar lo republicano en clave popular. Ambas estrategias, a pesar de sus distinciones, buscan centralmente la ampliación de la democracia desde una dirección política y popular.

Palabras clave: pueblo, democracia, sujetos políticos, Jacques Rancière, Ernesto Laclau.

\begin{abstract}
In this article are stated the political strategies of the popular and their relationship with democracy. Based on a critical dialogue between Ernesto Laclau and Jacques Rancière, two dynamics from which the popular is constituted as a political subject are proposed. In the first Rancerian strategy, the restructuring of public space and the re-appropriation of certain state devices institute the people as a political actor. However, this re-appropriation does not mean total inclusion of the popular subject to state dynamics, but instead a broadening of the meaning of these devices and a greater distance between the popular and the state. In the second populist Laclausian strategy, the articulation of
\end{abstract}


multiple demands based on empty signifiers and political antagonism suggests the possibility of thinking of a wide reconfiguration of the complex dimensions of the state, without this implying a complete reduction of the Popular to the state. This last strategy also opens up the possibility of thinking the Republic in a popular way. Both strategies centrally seek the expansion of democracy from a political and popular direction.

Keywords: people, democracy, political subjects, Jacques Rancière, Ernesto Laclau.

\section{Introducción}

En este artículo, se reflexionará en torno a las dinámicas de institución del pueblo como principal actor de la democracia y sobre la institución de lo popular en clave política desde una cuestión que considero central: los sujetos políticos populares no emergen ex nibilo, sino que son resultado de procesos de reapropiación y transformación de dispositivos medianamente constituidos: dispositivos tanto estatales como, considerados de manera más amplia, socioculturales. Esta reapropiación político-popular de lo "dado" se podría pensar desde dos estrategias: a) como reconfiguración del espacio público desde una emergencia "local" de lo popular y b) como una estrategia hegemónicopopulista que pretende reinstituir el amplio campo de lo social. Estas dos posibles dimensiones de la democracia, entendida como acción política de lo popular, serán abordadas a partir de un diálogo crítico entre Jacques Rancière y Ernesto Laclau.

\section{Igualdad y democracia: la emergencia política del pueblo}

En esta sección, se esbozarán algunas claves, a partir del filósofo Jacques Rancière, para pensar la democracia como emergencia y como institución política del pueblo. Esto supone la emergencia de nuevos sujetos en el espacio público, así como la reconfiguración de este espacio. Sin embargo, lo más resaltante será que esta emergencia de lo popular en clave política no significa la aparición de un sujeto ex nihilo, sino, en cambio, que este emerge a partir de una reapropiación compleja de lo "dado", en el caso de los dispositivos policiales, y crea a partir de sus 
brechas nuevas formas de verificación de la igualdad en el interior de estas instituciones o de manera más específica desde sus bordes.

En "Política, identificación, subjetivación", Rancière (2006a) menciona que podemos comprender la política como "un juego de prácticas guiadas por la presunción de la igualdad de cualquiera con cualquiera y la preocupación por verificarla" (2006a: 17). Esta se diferencia ${ }^{1}$ de la policía como lógica de gobierno que "consiste en organizar la reunión de los hombres en comunidad [...] y descansa en la distribución jerárquica de lugares y funciones" (2006a: 17). La política no posee un fundamento que pueda ser actualizado, sino, en cambio, da cuenta de la contingencia de lo que se pretende idéntico, es decir, de las identidades sociales, de aquellos repartos de lo sensible policial ${ }^{2}$.

1 Sin embargo, esta diferencia no es una estricta oposición, ya que, como menciona Quintana (2018), Rancière se vale de una metodología estético cartográfica. Laura Quintana, en "Más allá de algunos lugares comunes: repensar la potencia política del pensamiento de Rancière", parte de un distanciamiento de ciertas lecturas que se tienen en torno al pensamiento de Rancière, específicamente sobre la relación entre la policía y la política. Posiciones que podríamos denominar de la siguiente forma: dicotómicas, ontológicas, antiinstitucionalistas y de la emancipación efímera. Estas lecturas comparten un lugar común: en el pensamiento de Rancière, se elabora una distancia absoluta entre las lógicas de la dominación y las lógicas políticas. Desde aquí es que se producen lecturas simplistas sobre una respuesta frente a la dominación: como acción efímera y como acción antiinstitucionalista. Para desatar estos nudos, la filósofa pone en evidencia la metodología de la que se sirve Rancière para la reflexión sobre lo social: una metodología estético cartográfica. A partir de esta metodología, podemos ver que hay una relación en tensión entre las lógicas policiales como ciertas prácticas ensambladoras de sujeción y las lógicas políticas como prácticas desensambladoras que producen nuevos usos de los dispositivos policiales. Por ello, desde esta metodología los sujetos político-democráticos desde Rancière instituyen procesos de verificación de la igualdad que podrían sostenerse en el tiempo.

2 Siguiendo a Rancière (2014), se puede afirmar que el reparto de lo sensible se puede definir de la siguiente manera:

[...] un sistema de evidencias sensibles que permite ver al mismo tiempo la existencia de un común y los recortes que definen sus lugares y partes respectivas. Un reparto de lo sensible fija al mismo tiempo algo común repartido y ciertas partes exclusivas. Esta repartición de las partes y de los lugares se basa en un reparto de espacios, de tiempos y de formas de actividad que determina la forma misma en la que un común se presta a la partición y donde unos y otros son parte en ese reparto. (2014: 19) 
El sujeto de la política será el demos, que es "[...] almismo tiempo el nombre de la comunidad y el nombre de su división, el nombre del tratamiento de un daño" (2006a: 18). En tanto la policía daña la igualdad al pretender impedir su verificación, la política trata este daño reconfigurando el espacio público. El demos como sujeto de la política no es la invocación de un sujeto específico, sino el nombre de cualquiera, de un cualquiera, se podría decir, que se encuentra invisibilizado por un reparto de lo sensible sujetante o subordinante, por la policía. La política permite la manifestación de cierta ausencia, manifestación que produce una "[...] verificación de la igualdad de cualquier ser hablante con cualquier otro" (2006a: 19). Lo importante aquí es que no se trata de develar al sujeto "histórico" que se encuentra dominado, sino de pensar la producción de sujetos políticos en unos escenarios específicos y que su emergencia es posible a partir de la ruptura de lo que se pretende socialmente idéntico y no, en cambio, de mostrar lo "verdaderamente" idéntico. Desde esta mirada, no se trata de mostrar la "verdadera" acción "revolucionaria" o al único sujeto capaz de la transformación universal, sino de dar cuenta del proceso complejo a partir del cual se instituyen otras subjetivaciones políticas o sujetos políticos a partir de reapropiaciones de los dispositivos ${ }^{3}$ que se encuentran a la mano,

\begin{abstract}
Con esto, Rancière invita a pensar la política y la policía desde su dimensión estética, esto es, desde la manera en la cual se organizan los espacios sociales, estableciendo fronteras entre unos y otros, accesos a unos sujetos a lo común, como lugar donde se "definen" los parámetros de la convivencia a gran escala y excluyendo a unas mayorías de la posibilidad de la apropiación del espacio público. Se debe pensar este reparto como una heterogeneidad que alcanza una cierta estabilización o sedimentación de los espacios sociales a partir de un cruce de lógicas: movimientos policiales que ensamblan espacios y tiempos. No se debe olvidar que su naturaleza es heterogénea, pero que, sin embargo, sus pretensiones son las de cerrar su original contingencia.
\end{abstract}

3 El dispositivo, de manera breve, se puede comprender como disposición en dos sentidos: 1) disposición a actuar y a padecer: por un lado, una disposición a actuar en el espacio público por parte de sujetos específicos y, por otro, una disposición a padecer donde se evidencia la ausencia de acción política. Esta última disposición corresponde a los sujetos que se mueven exclusivamente en el espacio privado; y 2) disposiciones políticas, como aquellas que se abren en medio estas formaciones social jerárquicas y amplían el marco de acción de los sujetos antes vistos como puramente pasivos. Desde este punto de vista, el dispositivo tendrá una doble significación. 
como pueden ser el derecho, ciertas formaciones culturales, etcétera. La reflexión en torno a la institución de los espacios públicos ofrece algunas pistas más sobre los procesos de subjetivación política.

En otros textos, Rancière (2006a, 2006b) problematiza una mirada ciertamente ortodoxa del espacio público desde Arendt ${ }^{4}$ (2009). Esta filósofa establece una división rígida entre lo público y lo privado, entre el espacio de la praxis como espacio donde se generan las acciones políticas y el espacio de la poiesis, donde se establecen las relaciones privadas. De manera breve, es posible afirmar que, en el espacio público, desde esta visión, se tendrá a los sujetos políticos capaces de acción y, en el espacio privado, únicamente a los sujetos que atienden necesidades corporales y laborales, remitidas a lo privado. Rancière va a poner en cuestión esta dicotomía, ya que para él la política emerge cuando los sujetos remitidos al ámbito privado desestabilizan estas fronteras e incursionan en lo público. Esto supone una desidentificación de los sujetos privados y una reconfiguración de sus identificaciones, ya que pierden, en parte, la identidad provista por los mecanismos de poder subordinantes que les asignan un lugar en el espacio social. Esta desidentificación se da a partir de la ampliación de los marcos de acción de estos sujetos, y de nuevas formas de elaboración sobre sus identificaciones, sobre ese "nosotros" colectivo que es el pueblo.

4 Cabe señalar una cierta división rígida entre lo público y lo privado en Arendt (2009). El pensamiento griego dará los primeros trazos de la división entre una esfera privada donde encontramos las actividades concernientes a la supervivencia y al trabajo y a la esfera pública donde se manifiestan la acción y el discurso político. Esta separación será problematizada por Rancière, ya que a partir de ella no podemos reflexionar en torno a la institución de sujetos y espacios políticos. Sin embargo, cabe mencionar que esta separación rígida entre lo público y lo privado no es la única interpretación que se puede hacer del pensamiento político de Arendt. Siguiendo a Quintana (2012), se puede afirmar que para Arendt la división entre lo público y lo privado se constituye desde la posibilidad de la acción política en común, desde el esfuerzo por transformar ese común que habría sido capturado por una forma de administrar la vida que deshabilita la capacidad política de los sujetos en conjunto. Esta administración de la vida vuelve predecible la acción, así como también constituye posiciones de sujeto sociales que imposibilitan sus desplazamientos. 
Esta división entre lo público y lo privado se encuentra señalada en Arendt (2009) cuando se refiere al pensamiento griego, así como el diagnóstico que elabora sobre la modernidad como un gran espacio doméstico y productor de individuos-masa, privados de capacidades políticas. Estos son dos elementos problemáticos para pensar la política desde Rancière (2006a, 2006b). Por un lado, no es posible pensarla como un proceso democrático que desajusta el orden social dividido entre un modo de vida específicamente político, al cual estarían destinados unos sujetos, y otro modo de vida privado en el que se encontraría una mayoría incapaz de gobernar. Este desajuste de la división entre lo público y lo privado, en cambio, permite pensar la política como un proceso impuro y abierto en el que se muestran los desplazamientos de lo privado a lo público que reconfiguran la propia espacialidad pública. La acción de estos sujetos en un espacio antes negado supone no mantener el espacio público inalterado, sino verlo alterado por acciones que problematicen los dispositivos policiales, que actúen sobre ellos torciendo su "destino". Por otro lado, estas diferencias y este diagnóstico no permiten pensar la acción política en toda su complejidad: como acciones que actúan sobre ciertos ordenamientos policiales preestablecidos, como acciones reapropiadoras de dispositivos y lugares. Por ejemplo, la acción política se moviliza entre el dispositivo jurídico que verifica una igualdad y la cancela, y la reapropiación de este dispositivo por sujetos que se encuentran en los intervalos de nombres: entre la agencia y la pasividad, entre el proletario como posición de sujeto en un modo de producción y el dispositivo de subjetivación que supone una parte de los sinparte, entre la mujer como subordinada a unos roles sociales y como sujeto capaz de desdibujar la división público-privada, de ser un actor político; entre los jóvenes como agentes pasivos encargados de mantener la reproducción del capital a partir de su sacrificio y como sujetos capaces de un recambio social y político.

Con esto, el filósofo perfila una imagen en torno al espacio público como espacio conflictivo de manifestación de sujetos antes invisibilizados: 
[...] consiste en transformar este espacio de circulación [espacio público policial] en espacio de manifestación de un sujeto: el pueblo, los trabajadores, los ciudadanos. Consiste en refigurar el espacio, lo que hay que hacer, que ver y que nombrar. Es el litigio instituido sobre el reparto de lo sensible, sobre ese nemeïn que funda todo nomos comunitario." (2006: 72)

Habría que resaltar que el sujeto de manifestación política no es un sujeto preconstituido por fuera de la propia tensión de la acción política y su impacto reconfigurador, ya que la política opera en un espacio parcialmente sedimentado como ese reparto de lo sensible policial que abre un nuevo reparto que cuestione radicalmente la separación entre lo público y lo privado como separación entre la palabra (logos) y el ruido. En este sentido, consiste en "[...] hacer ver lo que no se veía, en entender como palabra lo que solo era audible como ruido, en manifestar como sentimiento de un bien y de un mal comunes lo que solo se presentaba como expresión de placer o dolor particulares" (2006: 73). La política, entonces, contamina la separación entre lo público y lo privado; lo que era remitido al mundo privado, como, por ejemplo, el mundo laboral y el de las mujeres se desplaza al ámbito público y se instituyen palabras y cuerpos con nuevas luminosidades. Es en este sentido que "la esencia de la política es el disenso [o desacuerdo]" (2006: 73). El desacuerdo ${ }^{5}$ que no es la confrontación de intereses preestablecidos, sino la "manifestación de una separación de lo sensible consigo mismo" (2006: 73), la separación del ordenamiento que se pretende uno. El desacuerdo supone la manifestación de un mundo otro que el constituido por un reparto policial, donde, por ejemplo,

5 Para instituir el conflicto político o desacuerdo es importante reparar en la dimensión temporal que abre la categoría del "como si". Esta categoría permite un escenario compartido para la acción política, "como si” existiera un mundo compartido, un mundo que es negado por las lógicas policiales. El "como si" es una virtualidad que permite las manifestaciones políticas, la voz de nuevos actores que discuten "como si" fueran parte activa en la comunidad. Claro que esta virtualidad no se la entiende como una mera idealidad sin consistencia material, ya que el "como si" tiene efectos materiales en las estructuras sociales e instituye cambios en las coordenadas del poder. 
"el obrero que argumenta el carácter público de un asunto 'doméstico' de salario debe manifestar el mundo donde su argumento es un argumento y manifestarlo para quien no tiene marco para verlo" (2006: 73). El espacio público, entonces, supone la institución de nuevos mundos y de posibilidades para ofrecer sentidos políticos. La institución del espacio público como lo que puede ser visto y oído por todos cobra un sentido nuevo a partir de las reflexiones de Rancière, ya que este espacio es constantemente reinstituido a partir de la emergencia de nuevos sujetos que ponen en suspenso la separación público-privada de los ordenamientos policiales. La posibilidad del espacio público supone la emergencia de la política como práctica democrática escandalosa que desplaza constantemente lo que se pretende natural, ya que abre la posibilidad de nuevas tareas a los sujetos y más específicamente dota de nuevos nombres a lo innominado o los recupera en una dirección muy distinta de la del contexto en el que fueron producidos.

Otra cuestión que cabe resaltar es que las acciones de los sujetos políticos trazan un universal conflictivo, es decir, configuran un "nosotros" como expresión de una colectividad que busca manifestar y darle un sentido al malestar social. Esta universalidad política se instituye en el "acto mismo" y demuestra la igualdad, es decir, no es un fundamento que develar, sino un operador que permite reconfigurar lo que se pretende idéntico. Para Rancière (2006b), la universalidad se encontrará en el resultado político de la implementación de los nombres de lo común: "humano" y "ciudadano". Estos serán nombres de lo común que expresan un lugar de disputa, ya que contribuyen a instituir un espacio público donde se polemiza en torno a la visibilidad y la escucha de los sujetos: "La acción política opone pues, a la lógica policial de separación de esferas, otro uso del mismo texto jurídico, otra puesta en escena de la dualidad entre hombre público y privado" (2006b: 86). Los derechos del "hombre" podrán ser politizados y más aún expresar la complejidad de la acción política distinta de la lógica normal del actuar. El nombre ciudadano permite la tensión entre la igualdad fijada por la ley y las desigualdades de los individuos remitidos al ámbito de lo privado, porque contribuye a crear ese intervalo entre igualdad jurídica y desigualdad social, e instituye un espacio de tensión 
(o espacio público) que las opone. Por otro lado, el nombre político "humano" genera la tensión entre la igualdad de capacidades y las restricciones de una ciudadanía establecida a partir de la exclusión de determinados "sectores de la vida colectiva" (2006b: 87). Estos nombres de lo político buscan crean un "espacio" donde se pongan en cuestión las formas sociales constituidas, aquellas diversas lógicas que buscan establecer jerarquías asignando lugares y funciones de manera rígida. El derecho, tomado políticamente como derecho humano que a partir de estos efectos de nombramiento amplía el marco de acciones de los sujetos, es un elemento importante para comprender la relación en tensión entre actores populares, que buscan verificar la igualdad, y lógicas policiales que, expresadas en ciertos ensamblajes estatales, sirven en algunos casos de impedimento para estas verificaciones. Abordemos a continuación estas tensiones.

Para terminar esta sección se profundizará, de manera breve, en la relación en tensión entre la acción política como emergencia democrática popular y lo "dado" o cierta institucionalidad estatal predada a la que se alude como reapropiación de los dispositivos policiales a partir de la política. Esto servirá para perfilar una cierta estrategia política desde lo popular que pone el énfasis en lo local.

Lo estatal no es un orden compacto y cerrado, sino un cruce de lógicas heterogéneas que instituye parcialmente ciertas regularidades sociales. Con Rancière, se mencionará que las lógicas estatales son parte de lo que se entiende como la policía, a pesar de no agotar el contenido de esta última. Este anudamiento parcial de la policía produce ciertos efectos de totalización. Así, una de sus dinámicas actuales será el consenso en torno a un "final" de la historia que supone la articulación entre globalización económica e instituciones representativas liberales.

6 Las lógicas policiales no son únicamente ensamblajes estatales, ya que también hay instituciones supraestatales que ejercen un cierto control sobre las decisiones individuales y colectivas. 
Si bien es cierto que lo estatal dentro de un marco globalizado ${ }^{7}$ se encuentra reducido, este sigue teniendo cierta eficacia social en cuanto a establecer ciertas limitaciones para la acción. Para Rancière, no se trata de crear un sujeto por "fuera" de las lógicas policiales-estatales, sino espaciamientos por dentro de estas instituciones y de realizar un trabajo entre sus brechas.

Para abordar esta relación en tensión entre la política y la policía, se debe partir de ciertos presupuestos ${ }^{8}$ : en primer lugar, que la política y la policía son lógicas que se entrecruzan en el mismo terreno social y no equivalen a sus niveles distintos. En segundo lugar, que la policía, si bien tiene efectos jerárquicos y subordinantes, puede ser reapropiada a partir de prácticas políticas. En tercer lugar, cabe señalar que uno de los campos más significativos donde se dan estas torsiones (o reapropiaciones) políticas es el "derecho9"; a partir de unos derechos

7 Ricardo Aronskind (2017) afirma que la globalización posee cuatro rasgos centrales interconectados: 1) debilitamiento del mundo del trabajo frente al poder del capital, 2) debilitamiento de las capacidades regulatorias estatales frente al poder corporativo privado, 3) debilitamiento de la influencia política y social de los sectores productivos frente a las lógicas de la rentabilidad financiera y 4) debilitamiento de las naciones periféricas frente a las naciones centrales. Estos cuatro rasgos darían cuenta del triunfo del poder financiero sobre un tipo de producción industrial. Esta dinámica de poder financiero significaría la subordinación del mundo de los trabajadores a los vaivenes de las finanzas, el debilitamiento del poder de los trabajadores, así como de su influencia en el Estado; la reducción del Estado por "corrupto" e "ineficiente" a mero agente que resguarda las aventuras del mercado, donde triunfa el poder corporativo; el florecimiento de una tecnología al servicio de las corporaciones; $y$, por último, la confección de políticas a escala global que debilitan la autonomía de las naciones periféricas. Sin embargo, podemos afirmar que en la globalización también se produce una formación estatal particular que muy a grandes rasgos se encuentra ligada a la influencia del poder financiero. Desde Rancière, el Estado sigue operando y teniendo una función de establecer jerarquías en el mundo social.

8 La argumentación que sigue a continuación tiene en cuenta algunos planteamientos de Laura Quintana (2020)

9 Delamata (2014) ofrece una reflexión sobre el papel del derecho en las movilizaciones sociales de la Argentina contemporánea, básicamente en el siglo Xxi. Dos casos son considerados por la autora: las demandas de vivienda por parte de los pobladores de las villas en Buenos Aires y la movilización política en torno a la sexualidad 
reconocidos, como los derechos humanos, se puede reclamar ciertos derechos ausentes, como el derecho a la salud, por ejemplo, que no se tiene en cuenta en las prácticas neoliberales actuales. Esto significa que se podría establecer un uso político de lo jurídico ${ }^{10}$. En cuarto lugar, que las dinámicas de intervención política pueden crear, también, sus propias formas de institución al recrear espacios donde se hacen visibles nuevos sujetos y nuevas problemáticas sociales.

De estos presupuestos, se puede inferir lo siguiente: a) con Rancière, se está frente a un uso particular del ejercicio políticodemocrático donde se interviene en ciertas dimensiones particulares de lo estatal con la finalidad de verificar una igualdad que es negada en el presente, b) que la democracia no será una forma de gobierno, sino una intervención político-popular que desajusta ciertas lógicas excluyentes de la policía, "obligando" a estas a afirmar una igualdad

y las relaciones de género que tiene como consecuencia el reconocimiento del matrimonio igualitario. Para Delamata, la comunidad legal se ha vuelto un actor político importante en la institución de un escenario igualitario que garantice los derechos de diversos sectores de la sociedad. Sin embargo, se podría introducir una relación más dinámica entre la comunidad legal y los movimientos sociales, pensando desde las coordenadas rancerianas, de tal forma que no sea tanto la "expansión del activismo jurídico" la condición de posibilidad de la reapropiación de los derechos por parte de los movimientos sociales, sino una relación más fluida entre la comunidad jurídica y los movimientos sociales lo que explique esta ampliación de los derechos. A pesar de este reparo, lo central aquí es la relación entre los movimientos sociales y el Estado como una tensión que genera la ampliación de derechos: mejoras en las viviendas y el reconocimiento de género. Con esto, no hay una pura separación entre el movimiento social, como un espacio puramente autónomo e incontaminado, y lo estatal, como pura maquinaria de opresión, sino una tensión entre reclamos e instituciones estatales que es mediada por una apuesta política desde el derecho.

10 Para Yacotzin Bravo (2019), el derecho no debe reducirse a una mera ficción de neutralidad "[...] independiente de las relaciones sociales, económicas y de poder" (2019: 57) ni tampoco a una pura dominación social, es decir, como un reflejo de las estructuras de dominación capitalista "[...] donde no existen posibilidades o potencialidades de transformación, resistencia o creatividad social en las cuales el derecho pueda tener cabida" (2019: 62), sino que debemos reparar en la dualidad del derecho: por un lado, este puede posibilitar la subordinación y, por otro, la transformación y la resistencia. Con esto, el derecho se entiende como un campo de disputa. 
negada, c) si bien esta igualdad puede manifestarse en ciertos derechos, estos no son una garantía de cumplimiento, sino que haría falta la manifestación del proceso político para la generación de nuevos espaciamientos de lo público, d) la inscripción de la igualdad se da en medio de las instituciones, torciendo la literalidad de la policía, verificando nuevos sentidos y usos, y e) la tensión entre lo dado (lógicas estatales) y la emergencia igualitaria se evidencia en el "derecho", ya que este se convierte en un campo de tensión: por un lado, es un dispositivo de regulación social y, por otro, un dispositivo abierto a otros usos que permiten, a partir de los movimientos populares, esa emergencia de lo político. Vía esta comprensión del derecho, podríamos comprender esta intervención de los sinparte en la arena pública: como intervención en el Estado y desde la generación de un campo propio, pero no aislado de la discusión pública. No se trata de un dualismo, por un lado, entre una unidad incontaminada y puramente dominadora como el Estado y, por otro, el campo de la pura horizontalidad del movimiento social, sino de una tensión, en tanto la movilidad política popular, desde Rancière, interviene localmente reconfigurando algunas dimensiones de lo Estatal e instituyendo sus propios procesos.

\section{Democracia, populismo e institución}

En esta sección, se abordará otra estrategia política de institución de lo popular en una dirección democrática. Esta estrategia será la dinámica populista-democrática que busca la reconfiguración de amplios espacios de lo cultural y lo estatal. La hegemonía populista ${ }^{11}$, a partir de Ernesto Laclau, da cuenta de una lógica particular de institución de lo popular o del pueblo que busca poner en cuestión una cierta monopolización de la voz pública que abre la posibilidad de la emergencia de diversos sujetos políticos, de una competencia

11 Para Laclau, el populismo como categoría únicamente analítica no da cuenta de un contenido ético-político, sino únicamente es una manera de conformar al pueblo. Sin embargo, este texto busca perfilar un tipo particular de populismo que confluya con los procesos democráticos; de aquí que se mencione la dinámica populista-democrática. 
por dotar a lo social de nuevos sentidos colectivos. Sin embargo, esta apertura del campo antagónico no será el único momento populista, ya que en tanto dinámica hegemónica busca de alguna manera estabilizar, aunque, de manera precaria, el campo social. De esto se infiere que una dinámica populista en tanto resignifica y estabiliza el amplio campo de lo cultural y lo estatal no se basa exclusivamente en una distancia con lo estatal, sino que sugiere otras maneras de comprender lo estatal a partir de esta emergencia del campo popular, como la formación de nuevos gobiernos populares a partir de una reapropiación y una transformación del Estado.

Para abordar esta estrategia, se dividirá esta sección en tres partes. La primera tiene que ver con lo que denomino el núcleo de historicidad del populismo, que permite comprender la dinámica temporal y espacial en la que descansan el populismo y la hegemonía. En la segunda parte, se dará cuenta del populismo y de su relación con la hegemonía: las lógicas que esto supone. En la última parte, se presentará la estrategia políticohegemónica del populismo y su compromiso con la reconfiguración de amplios campos del espacio público, más específicamente con la posibilidad de resignificar el espacio de lo estatal desde una apuesta populista-democrática. Desde aquí, se examinarán las posibilidades que abre el populismo para pensar en un republicanismo popular. En este sentido, esta sección sugiere una cierta reconstrucción de la teoría de Ernesto Laclau desde su orientación democrática y su estrategia por reconfigurar el Estado desde la emergencia político-popular.

\subsection{Historicidad: el juego entre el tiempo y el espacio}

La historicidad en la obra de Ernesto Laclau tiene que ver con un juego entre las acciones políticas y las sedimentaciones sociales o entre el tiempo como apertura del campo de posibilidades y el espacio como establecimiento de formaciones sociales. En este sentido, en la misma dirección que se analizan las relaciones entre la policía y la política en Rancière, la política y lo social en Laclau no serán unidades incontaminadas, sino que expresarán un complejo juego donde ambas se necesitan recíprocamente. Más aún, desde el pensamiento de Laclau, habría un cierto desplazamiento continuo entre la reactivación de la 
política y la sedimentación de lo social. Para comprender esta dinámica, en primera instancia, presentaré de manera un tanto abstracta las relaciones entre el tiempo y el espacio a partir de una reflexión en torno a la categoría de dislocación.

La dislocación, de manera un tanto general, tiene que ver con los contextos de crisis sociales que, como veremos más adelante, se manifiestan a partir de la emergencia de demandas sociales. Esta dislocación posee tres dimensiones: la temporalidad, la posibilidad y la libertad; cabe notar que todas ellas se encuentran en estrecha vinculación. Para nuestro argumento, únicamente repararemos en las posibilidades que abren tanto la concepción sobre la temporalidad como la de posibilidad para pensar lo que llamo el núcleo de historicidad en la teoría política laclausiana. Para ello, presentaré el desarrollo de esta primera dimensión a partir de la primera parte de las Nuevas reflexiones sobre la revolución de nuestro tiempo.

La reflexión en torno a la temporalidad como una de las dimensiones de la dislocación comienza estableciendo una estricta separación entre lo que considera como espacio y tiempo. Por un lado, el espacio es identificado como una estructura simbólica total, gobernada por leyes internas (o repeticiones) que hacen imposible todo cambio. Por otro lado, el tiempo parece identificarse como el puro evento completamente externo a este espacio determinado. Sin embargo, esta primera aproximación algo rígida progresivamente se va haciendo más compleja y da paso ya no a una pura dicotomía entre espacio y tiempo, sino a una interacción entre los mismos. Un primer acercamiento entre ambos sugiere que habría una espacialización de la temporalidad a partir de una "reducción de su variación a un núcleo invariante que es un momento de la estructura pre-dada" (2000: 58). Con esto, se está frente a una interacción conservadora, ya que se impone la ley rígida del espacio frente a la apertura del tiempo. No habría ningún tipo de hegemonización del tiempo sobre el espacio, ya que este es entendido como un puro cambio. Todavía el argumento es algo rígido, ya que no muestra un complejo intercambio entre lo espacial y lo temporal, sino únicamente un dominio de lo uno sobre lo otro. Siguiendo con la posibilidad como segunda dimensión de la 
dislocación, podremos notar un mayor desarrollo de la interacción de ambos. La posibilidad, para ser "real", debe mostrarse como una apertura a diversas intervenciones sobre lo dado, pero no como una única vía posible. La posibilidad en sentido puro muestra que no existe algo así como un fundamento al cual se pueda remitir los cambios. Desde esta dirección, Laclau menciona que la fuerza del tiempo siempre vence al espacio, en tanto no puede concebirse un espacio enteramente rígido. Esta última cuestión nos permite dar un paso más para salir de la primera reducción a la que parece someternos Laclau, ya que, si siempre el tiempo vence al espacio, quiere decir que no se podrá concebir un espacio enteramente cerrado, sino que incluso los espacios sociales que se pretenden más impermeables o, para decirlo de otro modo más autoritario, se encuentran atados a determinadas dinámicas temporales, deben partir de esta ausencia de fundamento para constituirse. Es en este sentido que estos espacios rígidos no son máquinas soportadas por funcionamientos mecanicistas, sino complejas relaciones de poder que pretenden ocultar la contingencia que se encuentra inscrita en su núcleo. No hay estructura completamente centrada. Sin embargo, su argumento no queda ahí, sino que nos muestra un último elemento que permite pensar lo que se entiende como la historicidad de la política. Laclau, líneas más adelante, afirma lo siguiente:

Una vez más debemos insistir, para evitar malos entendidos que la dislocación de una estructura no significa que todo pasa a ser posible, o que todo cuadro simbólico desaparece, simplemente porque en un tal universo psicótico no podría haber dislocación alguna: para dislocar una estructura debe haber estructura en primer término. La situación de dislocación es la situación de una falta que presupone la referencia estructural. Hay temporalización de los espacios, o una ampliación del campo de lo posible, pero esto tiene siempre lugar en una situación determinada: es decir, en una en la cual hay siempre una estructuración relativa. (2000: 59)

Tanto el tiempo como la posibilidad "actúan" en relación a una cierta estructuración y así también la estructura se constituye en relación con una dislocación que supone su condición de posibilidad. Este juego 
entre el tiempo, la posibilidad y el espacio nos muestra la interacción que se encuentra en la misma entrańa de los sujetos políticos. Estos no son comprendidos como meros eventos sin ningún tipo de relación con la estructura, sino que interactúan a partir de la fuerza del tiempo en medio de una estructura abierta, reconfigurando sus elementos a partir de sus brechas. Esto significa, como se discutirá más adelante, que la resignificación colectiva y popular del populismo no supone una articulación de demandas completamente externas a la estructura social que construye otra estructura totalmente nueva. No existe el "borrón y cuenta nueva", sino una compleja relación con lo "dado" que permite la reconfiguración de sus elementos. La hegemonía populista en esta dirección de transformación política o democrática debe comprenderse en este núcleo de historicidad, en el que lo pasado es resignificado en el presente, cuando a partir de las crisis sociales se posibilita una apertura del horizonte político. A continuación, se seguirá avanzando en esta idea de la historicidad a partir de algunas cuestiones que aparecen en "Poder y representación", ensayo que se encuentra en Emancipación y diferencia, texto del pensador argentino.

Para Ernesto Laclau, la política será un conjunto de decisiones o actos de poder que se manifiestan en terrenos indecidibles o contingentes, es decir, que no se puede prever con absoluta claridad el devenir de estos. Sin embargo, estos actos de poder no quedarían como meros acontecimientos que no sedimentan las relaciones sociales, sino que estos producen sedimentaciones que se entienden como lo social: "Si la politica es el conjunto de las decisiones tomadas en un terreno indecidible -es decir, un terreno en el que el poder es constitutivo-en tal caso lo social solo puede consistir en las formas sedimentadas de un poder que ha borrado las huellas de su propia contingencia" (1996: 182).

Hay un tipo de relación compleja entre estos actos políticos contingentes y la sedimentación o la estabilización de los mismos en lo social. No se debe comprender esto de manera un tanto dicotómica: por un lado, lo puramente contingente como la política y, por otro, lo meramente sedimentado como lo social, porque para poder reinscribir estos actos de poder políticos es necesaria una previa inscripción, un terreno abierto a nuevas resignificaciones colectivas a partir de la política. 
Por ello, las voluntades colectivas se redefinen y no se definen desde el puro vacío. El hecho de que las identificaciones políticas no dependen de alguna "racionalidad social a priori" (1996: 160) no significa que se instituyen ex nibilo. No hay una "voluntad" que se rearticule por fuera del campo social:

[...] es obvio que la cuestión no puede ser resuelta sobre la base del simple subterfugio que rearticularía en torno a su proyecto los elementos dispersos. La relación entre sujeto y estructura es, en realidad, mucho más compleja que lo que esta visión simplista de lo que está implicado en una articulación hegemónica parece sugerir. $(1996: 160,161)$

Con esto, la articulación político-contingente de la hegemonía la comprendo como una resignificación por dentro del campo social o, mejor aún, en medio de sus brechas, reelaborando nuevos sentidos de sus elementos. Esto implica la necesidad de un diálogo con lo previamente sedimentado, ya sea este una formación cultural general o más específicamente estatal, con el fin de redefinirla, de dotarla de nuevos usos.

En este núcleo reflexivo de la historicidad como un juego complejo entre lo temporal y lo espacial o entre lo político y lo social es donde se debe comprender la reflexión sobre el populismo desde una dirección democrática. Cabe mencionar algunas cuestiones muy breves sobre el populismo de Ernesto Laclau para entenderlo como un proceso dinámico que busca reinstituir ampliamente lo social.

\subsection{Populismo y hegemonía}

La hegemonía desde la mirada de Ernesto Laclau será entendida como una particular intervención desde el lenguaje y los afectos ${ }^{12}$ que permite comprender unas particulares dinámicas de constitución del pueblo como sujeto político. Laclau, en La razón populista, afirma lo siguiente: "una relación hegemónica es aquella en la cual una determinada particularidad significa una universalidad inalcanzable" (2006a: 143).

12 Por motivo de espacio, no se abordarán las posibilidades que abren estas dimensiones. 
Este transcurrir de lo particular hacia lo universal se evidencia desde el paso de una demanda particular o democrática hacia la constitución de una demanda popular o universal-particular.

Para Laclau, no se debe tomar como punto de partida para el análisis social al grupo previamente constituido, ya que este no es un referente homogéneo, sino resultado de "[...] una articulación de demandas heterogéneas" (2006b). Las demandas son experiencias colectivas frente a diversas situaciones de insatisfacción social. Estas experiencias podrán variar de intensidad: desde una simple petición a una autoridad local hacia una mayor insatisfacción presentada como un reclamo que pueda comprometer gran parte del orden institucional. Estas experiencias de insatisfacción estarán remitidas muchas veces a insatisfacciones en torno a necesidades vitales inmediatas. Por eso, no es azaroso que Laclau (2006a) ofrezca, entre sus ejemplos "imaginarios" e históricos, demandas por la vivienda, reclamos alimentarios, de transporte, salud, etc., dando cuenta de que son demandas ligadas a ciertas necesidades vitales, de manera implícita se encuentran vinculadas a la dimensión corporal y pueden diferenciarse entre demandas democráticas y demandas populares. Por un lado, las primeras serán peticiones más o menos aisladas que se realizan a alguna autoridad inmediata para que las resuelva. Esta experiencia de insatisfacción podría ser reencauzada por el sistema institucional; sin embargo, serán también posibilidades de demandas más amplias. Por otro lado, las demandas populares serán el resultado de vínculos entre diversas demandas democráticas y una frontera antagónica entre un nosotros, el pueblo, versus un ellos, la "oligarquía".

El paso de una demanda democrática hacia una demanda popular o universal es siempre un proceso inacabado, ya que lo popular se constituye parcialmente. Laclau reflexiona sobre este proceso a partir de lo que entiende como las dimensiones de la fractura del espacio social.

Tres de las dimensiones de la fractura no se encuentran desligadas, sino que se entrecruzan para dar cuenta de una fractura de lo constituido socialmente. La primera dimensión tiene que ver con la experiencia de la dislocación. Para Laclau (2000), los sujetos sociales poseen una dimensión primaria de dislocación imposible de suturar. En este caso, 
esta experiencia de dislocación o de falta tiene que ver con aquellas insatisfacciones sociales o demandas que generan brechas sociales. La dislocación, entonces, podrá considerarse como la demanda insatisfecha frente a un poder insensible (Laclau, 2006a: 113). En momentos de amplias crisis sociales, esta falta podrá emerger con todo su potencial de transformación, así como dar cuenta de la contingencia que habita el corazón de los órdenes sociales. En la segunda dimensión, se evidencia el pasaje de las demandas democráticas a las populares. Esto supone una articulación equivalencial entre diversas insatisfacciones. Aquí, se juega una amplia experiencia social o, podría decirse, una mayor intensidad en la experiencia social de frustración, pero también de anhelo de un cambio. Un entramado de diversas demandas logra un tipo de vínculo a partir de la dislocación, pero también de la expectativa por superarla. La tercera dimensión tiene que ver con la tensión entre la equivalencia y la diferencia o entre la demanda popular y la democrática. Habría que señalar algunas cuestiones en relación con esto: en primer lugar, que la relación entre demandas supone una alteración de las mismas; esto quiere decir que no se relacionan como unidades determinadas que no se modifican en la interacción y, en segundo lugar, que se hace necesario, siguiendo a Laclau (2006a), que una demanda democrática se constituya como el denominador común de la equivalencia: esta adquirirá por "razones circunstanciales" una cierta centralidad. Este común a partir de la relación entre demandas supone un común que se constituye a partir de las experiencias de frustración y del anhelo por alcanzar la superación de la situación de crisis; por ello, es un común conflictivo que genera identificaciones en el campo popular. Aquí, los significantes vacíos $^{13}$ serán importantes para comprender este proceso parcial de universalización, que intentan manifestar una cierta plenitud ausente. Los significantes vacíos expresarán la heterogeneidad de las demandas y las dotarán de sentidos que expresen tanto el malestar social, como el deseo de superación. El paso de una demanda democrática hacia su

13 Los significantes vacíos son nombres que aglutinan a su alrededor las demandas sociales: tanto las expectativas de superación de la insatisfacción de la crisis social como a los responsables de la crisis. Por ello, estos son significantes conflictivos que dan "sentido" a las crisis sociales. 
universalización popular será lo que Laclau comprende como populismo, que cabe mencionar aquí como hegemonía populista, que resalta esa articulación indisoluble. Esto quiere decir que cuando un contenido particular o una demanda democrática asume la representación de la totalidad de las demandas, es decir, cuando se articula con ellas, instituye una universalidad. Sin embargo, en tanto la política, como se mencionó anteriormente, parte de un terreno contingente, no se puede saber de antemano qué demanda será la que encarne esa totalidad imposible que es el universal hegemónico. Esto quiere decir que las relaciones hegemónicas se conforman a partir de luchas contingentes. Volviendo a Gramsci, Laclau afirma lo siguiente:

Gramsci formuló su argumento político en términos similares: cuál fuerza social se va a convertir en la representación hegemónica de la sociedad como un todo es el resultado de una lucha contingente; pero una vez que una fuerza social particular pasa a ser hegemónica, permanecerá como tal por un período histórico. (2006a: 148)

Aunque, si bien el transcurrir de lo particular a lo universal es contingente, "no puede cambiar a voluntad" (2005: 148). Así, también, cabe afirmar que la contingencia se encuentra en relación con lo instituido; no se parte de una pura contingencia, sino de ciertas instituciones sociales que permiten reelaboraciones. No hay elementos primarios desnudos de sentidos, sino que se encuentran "sobredeterminados desde su mismo comienzo" (2006a: 148). Con esto, la articulación de demandas desde el populismo responde al núcleo de historicidad antes presentado, donde se reelaboran elementos pasados y presentes, y se los dota de nuevos sentidos colectivos que permitan transformar las instituciones en crisis. La forma más "concreta" de presentar la hegemonía como materialización política popular será vía lo que Laclau entiende como populismo.

La articulación entre lo particular y lo universal tiene efectos sociales concretos: "se sedimenta en prácticas e instituciones" (2006a: 138). Esto quiere decir, siguiendo a Laclau, que esta articulación popular no se encuentra en el nivel de las "palabras", sino que adquiere una 
materialidad, una "fijeza institucional". Más aún, el pensador argentino menciona lo siguiente:

Esto es lo mismo que afirmar que cualquier desplazamiento hegemónico debería ser concebido como un cambio en la configuración del Estado, siempre que este no sea concebido, en un sentido jurídico restringido, como la esfera pública, sino en un sentido amplio gramsciano, como el momento ético político de la comunidad. (2006a: 138)

La estrategia hegemónica populista supone, entonces, una amplia transformación de lo estatal tanto en su sentido jurídico como en su sentido, se podría decir, cultural como mediación social que permite dar sentido a las diversas prácticas ${ }^{14}$. Esta estrategia de lo universal populista, dinámica e histórica, busca transformar ampliamente el campo de lo social, resignificar el espacio a partir de la contingencia que abre el tiempo.

¿Cómo podría comprenderse esta relación entre el populismo y las instituciones estatales? Es verdad que Laclau brinda pocas pistas al respecto, ya que no desarrolla la imbricación entre el populismo y las instituciones estatales; por ello, se darán algunos pasos más adelante junto con Laclau o a partir de él y pensar esta relación entre el populismo y las instituciones estatales a partir del republicanismo popular. Para complementar las posibilidades que Laclau abre, se mancionarán algunas ideas de Eduardo Rinesi (2019) sobre lo que él entiende como republicanismo popular.

\subsection{Populismo y republicanismo}

Eduardo Rinesi (2019), en "Populismo, democracia, república (notas sobre libertades y derechos)", pone énfasis en un tipo de libertad popular que rebalsa los límites de las libertades "liberales", como son

14 Acaso no se puede notar que hay siempre una relación entre el derecho y las convenciones, tal como lo sugiere Rousseau: "Pero el orden social supone un derecho sagrado que sirve de base a todos los otros. Sin embargo, ese derecho no es un derecho natural: se funda en convenciones. Trátese, pues, de saber cuáles son dichas convenciones" (1985: 27). 
la libertad positiva y la negativa. Esta libertad del pueblo se encuentra más allá del sujeto del liberalismo: el individuo, tanto en su versión de individuo capaz de actuar sin coerciones como del individuo capaz de participar en el espacio público. La libertad del pueblo, en cambio, nos acerca a la posibilidad de constituir un sujeto colectivo, a pesar de su parcialidad, capaz de representar una nación y de ofrecer -por qué nouna decisión soberana y colectiva. El pueblo como actor político tiene como dimensión central el antagonismo, es decir, busca resignificar un campo social en crisis a partir de la lucha contra las oligarquías. Este no es ni un individuo que busca una pura decisión autónoma libre de coerciones ni un individuo "racional" y compacto que participa en un espacio público previamente constituido. El pueblo, en cambio, constituye los espacios públicos de manera colectiva, a partir de los malestares sociales y enfrentándose a los responsables de las crisis. Lo que quisiera destacar aquí es que este sujeto político, democrático y popular no se encuentra de espaldas a las instituciones, sino que forma algo así como una amalgama con un tipo de republicanismo, que Rinesi define, a partir de una muy breve exploración en torno a la figura de Maquiavelo, como republicanismo popular ${ }^{15}$. A diferencia de un republicanismo aristocrático, que en buena cuenta pone como principal sujeto a una élite virtuosa y capaz de gobernar, el republicanismo popular pone énfasis en el conflicto protagonizado por el pueblo y su posibilidad de crear instituciones. El populismo en esta dirección democrática y antagónica es republicano, más específicamente republicano popular y no aristocrático. Si este tipo de populismo republicano, para decirlo de una vez, tiene como eje central la democratización en tanto proceso que verifica constantemente la igualdad a partir de la reactivación de la universalidad de los derechos, porque intenta construir un Estado que garantice el bienestar común. Esto supone pensar otra posibilidad de

15 Habría que subrayar que, en los republicanismos populares, las libertades liberales no quedan borradas, sino incluso potenciadas. El propio Ernesto Laclau se encontraba a favor de lo que él entendía como un republicanismo cívico: “[...] pero la condición de una sociedad democrática es que estos espacios públicos deben ser plurales: una sociedad democrática es, desde luego, incompatible con la existencia de un único espacio público. A lo que debemos aspirar es a un 'republicanismo cívico' múltiple” (209). 
lo estatal, no de manera ingenua como un espacio a partir del cual se generaría una plenitud social, sino como espacios, a veces contradictorios, que garanticen, con sus limitaciones, la libertad de los pueblos; esto significa el ensanchamiento de espacios públicos, es decir, que los sujetos antes excluidos del "reparto de lo sensible" puedan obtener un sostén material y simbólico para desplegar sus acciones.

Quisiera cruzar aquí algunos elementos del populismo laclausiano y de la mirada republicana desde Rinesi. Lo primero que podría afirmar es que la libertad republicana no se origina en el momento en que se encuentran aseguradas las condiciones materiales de los sujetos, sino que esta libertad emerge en el momento mismo del conflicto, donde los sujetos, por ejemplo, precarizados por las actuales formas del neoliberalismo, demandan mejores condiciones de vida, se organizan y reelaboran la situación de crisis, y se permiten actuar y transformar el espacio público. En las situaciones de crisis sociales, hay posibilidad de crear las libertades colectivas que son armas contra las desigualdades sociales. Esto es relevante, ya que no se trata, de manera un tanto esquemática, de que un líder dote verticalmente de sentido a las manifestaciones populares, sino de intercambios complejos entre representantes y representados.

Este populismo de orientación democrática laclausiano abre las puertas para pensar otra estrategia política de lo popular: la articulación compleja de demandas sociales, el trazado de una línea antagónica entre el "nosotros" del pueblo contra las oligarquías o las corporaciones económicas -para estar en sintonía con nuestros tiempos- como elementos que posibilitan una amplia transformación de lo estatal como una reconstrucción de las lógicas del Estado en clave republicano-popular.

\section{Dos estrategias políticas del pueblo: a modo de conclusión}

La primera conclusión tiene que ver con el carácter profundamente popular de la cuestión democrática. La democracia se deberá comprender a partir de la emergencia de lo popular en clave política, si bien esta emergencia no posee una sola estrategia de constitución del pueblo. El pueblo como actor político da cuenta de una reconfiguración del orden dado, más aún que las identidades asignadas desde un poder sujetante (o 
subordinante) son contingentes, pueden ser puestas en cuestión a partir del trabajo político del pueblo que resignifica colectivamente el campo social. Se trata de poner en evidencia la contingencia a partir de la cual se encuentran elaborados los ordenamientos sociales y la posibilidad de resignificarlos colectivamente, que redunda en la ampliación de las libertades, de la justicia social.

La segunda conclusión tiene que ver con las dinámicas a partir de las cuales se constituye el pueblo como sujeto político. El sujeto político popular, para decirlo en términos sencillos, no se constituye ex nihilo, ya que el trabajo del pueblo en clave política tiene que ver con la resignificación; es decir, con dotar de nuevos sentidos a lo "dado", más allá de los ordenamientos sociales sedimentados. El pueblo resignifica lo social a partir de un trabajo en medio de sus brechas: en algunos casos, dota de nuevos usos a dispositivos que cumplían una función de subordinación y los vuelve "herramientas" que verifican una igualdad negada; en otros, se evidencia una elaboración mayor de lo social, que se reapropia ampliamente de los diversos campos de lo estatal y pretende reinstituir un gobierno popular, ya que abre la posibilidad de reconfigurar la república en clave popular. Estas reapropiaciones suponen la posibilidad del ensanchamiento de la capacidad del mismo dispositivo, es decir, que no estamos frente a un simple uso de una herramienta que no se modifica, sino de su modificación a partir de sus nuevos usos. En esta medida, ninguno de los dos trabajos supone estrategias por fuera de las estructuras o las lógicas sociales, sino elaboraciones complejas en medio de sus brechas, que ensanchan el sentido social a partir de la emergencia colectivo-popular. Por ello, estas estrategias no se encuentran en las coordenadas de aquellas perspectivas que plantean un purismo comunitario que se elabora por fuera de las lógicas del poder. Estas perspectivas que denominaría esencialistas parten de una premisa que es problemática: el movimiento social es completamente autónomo de las lógicas estatales y supraestatales; no se valen de sus recursos, sino de sus propios elementos para constituirse. Las acciones políticas no son elaboraciones que parten de la nada, sino una compleja relación con lo presente y lo pasado que intenta mantener abierto el campo de posibilidades futuras. 
La tercera conclusión tiene que ver con las estrategias diferentes que posee el pueblo para conformarse como sujeto político. En este artículo, se han mostrado dos posibles estrategias. Con esto no se quiere afirmar que no pueda haber más elaboraciones estratégicas. Una primera estrategia, la considerada a partir de Rancière, supone la emergencia de lo popular a partir de la quiebra de la orientación ortodoxa de las fronteras entre lo público y lo privado. La manifestación de problemáticas como el trabajo, por ejemplo, en el campo público, supone llevar ciertas cuestiones que se entienden como privadas al campo de lo público. Este cuestionamiento de estos límites permite la emergencia de un universal político-popular que verifica una igualdad negada. Los derechos humanos, en estas coordenadas, permiten la elaboración de estas identificaciones imposibles; es decir, el desplazamiento del lugar fijado por la policía, la puesta en cuestión de ciertas jerarquizaciones sociales. Las acciones políticas populares presuponen una base de igualdad que es negada por el orden policial presente. Esta verificación de lo igualitario se elabora a partir de la reapropiación del derecho; en todo caso, reactualiza la igualdad que se supone forma parte de su núcleo. En esta estrategia, las manifestaciones populares logran desestabilizar las lógicas policiales estatales al punto que estas últimas puedan reconocer ciertos derechos negados. Lo particular de esta estrategia de lo popular es que no pretende materializarse por medio de representaciones estatales: tensa las lógicas subordinantes de lo policial o lo estatal, se vale de sus recursos, como el derecho mismo, pero establece una distancia frente al Estado que posibilita ciertas autonomías locales. La segunda estrategia corresponde a la estrategia populista trabajada por Ernesto Laclau y complementada, de manera breve, por Eduardo Rinesi. La estrategia populista-republicana se constituye a partir de la dinámica hegemónica de los siguientes elementos: 1) la articulación de demandas particulares, 2) la equivalencia de estas demandas a partir de su vinculación con un contenido particular que las represente, 3) la conformación de una frontera antagónica entre un "nosotros" (el pueblo) contra un "ellos" (la oligarquía), o un sector minoritario que monopoliza la decisión pública, 4) la posibilidad de este actor de institucionalizarse por medio de ciertas dinámicas estatales que garanticen infraestructuras públicas. 
En la lógica populista-republicana, lo popular, si bien no elimina la distancia frente a lo estatal, ya que los espacios públicos a partir de Laclau no se agotan en el Estado, sí la recorta en mayor medida. Se está frente a la posibilidad de una dinámica democrático-popular de lo estatal. No es intención del artículo establecer una valoración de una o de otra estrategia, ya que a ambas responden a diversos momentos y decisiones políticas. El proceso populista-democrático de ruptura amplia de lo imperante no se encuentra "a la vuelta de la esquina"; son procesos que "aparecen 16" en algunos "momentos" particulares de la historia. Así, también, las respuestas populares a lo Rancière tienen coyunturas particulares, procesos en los que se ensamblan dinámicas de contestación y organización (porque no se está frente a manifestaciones fugaces) donde se privilegia el componente local de disputa y donde no se apuesta por la conformación amplia de nuevas lógicas de gobierno a partir de la reconfiguración de lo estatal.

Para complementar lo mencionado en la tercera conclusión, cabría colocar, de manera breve, dos posibles ejemplos de reconfiguración del campo social a partir de estas dos estrategias: por un lado, una estrategia más ranceriana, a partir de la movilización popular encarnada por el Congreso de los Pueblos y la Comunidad de Paz de San José de Apartadó en Colombia y, por otro lado, una más laclauseana, a partir de la creación de la ley de Asignación Universal por Hijo en Argentina.

Laura Quintana, en "Un derecho que no es un derecho. El derecho como estructura política del desacuerdo" (2015), realiza una reflexión en torno a la constitución de los movimientos populares y los derechos políticos. Para ello, da cuenta del potencial político de dos movimientos populares: el Congreso de los Pueblos y La Comunidad de Paz de San José de Apartadó en Colombia. El artículo explora "cierta manera de comprender y movilizar el derecho por parte de algunas experiencias de organización popular [...]" donde "[...] se crean ya nuevas prácticas y formas de asociación que experimentan con nuevas

16 Este aparecer, para recalcarlo, no es un puro acontecimiento de ruptura, sino, como se mencionó, la reconfiguración de amplios campos sociales y la resedimentación de sus sentidos. Cuando se menciona "sentidos", no se afirma un cambio de palabras, sino una transformación material de la sociedad. 
posibilidades de ser y de vivir en común" (2015: 71). La manifestación popular cuestiona una visión de la democracia entendida como defensa de los mecanismos institucionales preexistentes y considerados como invariables. Por ello, la movilización popular supone el exceso de estos mecanismos de representación, sin por ello crearse completamente por fuera de ciertas instituciones existentes. No se trata tanto de enfocarse en unos derechos previamente reconocidos por el Estado, sino en el propio proceso de generación de subjetividades políticas entre las brechas de lo instituido más allá, en algunos casos, de algunos derechos establecidos, que evidencian que hay otras formas de ser en conjunto que exigen formas de autonomía. Desde este punto de vista, se puede comprender, siguiendo a la filósofa Laura Quintana, la emergencia de ciertos movimientos populares colombianos: el Congreso de los Pueblos y la Comunidad de Paz de San José de Apartadó. Las acciones políticas de estos movimientos crean escenarios inéditos, en tanto visibilizan demandas y derechos que no se habían tenido en cuenta como existentes. Es así que la configuración de estos espacios parte de la presencia conflictiva de lo popular.

El Congreso de los Pueblos nace el 10 de octubre de 2010 y agrupa a diversos movimientos sociales. Se está frente a un Congreso que articula un poder popular diferente del Congreso, entendido como dispositivo parlamentario, ya que, a diferencia de este, el Congreso de los Pueblos articula un poder popular, siguiendo a Quintana (2015), que produce nuevas formas de ser en conjunto. Lo que confronta un modelo de desarrollo económico dominante es la noción de buen vivir que se encuentra atravesada por diversas prácticas sociales y compresiones teóricas. Por ello, este Congreso tiene un carácter heterológico, en tanto dentro de él conviven diversas lógicas, prácticas políticas y teóricas:

[...] apuntan a configurar formas de ser juntos que permitan generar economias solidarias y de mayor autogestión local, preocupadas por posibilitar usos no meramente extractivos de la tierra, y con ello formas de producción y de distribución más equitativas y más equilibradas con la naturaleza (2015: 80). 
Esta movilización colectiva no espera que estos problemas sean resueltos por los "gobernantes", sino apunta a cierta autonomía de las organizaciones sociales, sin estar por ello completamente fuera de las lógicas de gobierno. Tiene ver que con otra forma de democracia a partir de la autoorganización y la autogestión de sus territorios.

Así, también, está la conformación de la Comunidad de Paz por parte de los sobrevivientes de las masacres que perpetuaron los militares a las personas del caserío de San José de Apartadó. Esta comunidad se funda como un territorio neutral, es decir, que no se articula con ninguno de los actores del conflicto: ni con las guerrillas, los paramilitares o los militares. La soberanía de esta Comunidad de Paz se pretende más allá de una cierta lógica de soberanía estatal, así como de la lógica de amigos-enemigos de los grupos armados. Sin embargo, esta soberanía no se establece fuera de otras dimensiones del poder, ya que se moviliza también a partir de los derechos internacionales que legitiman sus autonomías, así como de ciertas normas nacionales que reconocen sus autodeterminaciones. Hay una reutilización de la ayuda humanitaria a partir de sus propios discursos y prácticas.

Lo que ambos movimientos populares permiten comprender es una estrategia de lo popular que resignifica los derechos a partir de la creación de escenarios polémicos donde los sujetos cuestionan determinadas formas de organización que atentan con sus prácticas culturales y sociales. Con esto, no se trata tanto de que el Estado conceda a los sujetos derechos a partir de un reconocimiento "generoso", sino de que son los movimientos populares los que tensan el orden existente y posibilitan nuevas formas de ser en conjunto, así como nuevos derechos reconocidos por el Estado. Por ello, estas movilizaciones político-populares no se inventan fuera de las relaciones de poder, sino que posibilitan resignificaciones de derechos existentes y amplían su marco de acción. El acento de esta estrategia se encuentra en la reelaboración de derechos existentes, así como en la posibilidad de creación de nuevos derechos a partir de la emergencia de los sujetos políticos. Así, esta estrategia también pone el acento en una manera particular de manifestación de lo popular que tendría que ver con la autogestión local. 
Luciana Cadahia, Valeria Coronel, Soledad Stoessel y Julio Guanche, en "Hacia una nueva lógica del populismo: de la ruptura de las instituciones a la institucionalidad populista" (2020), proponen una reflexión del tránsito entre las demandas sociales y su institucionalización estatal en la Argentina de Cristina Fernández. Para esto, plantean un análisis de la conformación de la ley de Asignación Universal por hijo en Argentina. Este planteamiento pone en cuestión las visiones que no permiten considerar al populismo como posibilidad de reconfiguraciones en el plano institucional-estatal; de ahí que sea necesario poner atención en las cristalizaciones institucional-estatales a partir de las irrupciones plebeyo-populistas. Esto significa reflexionar en torno a las lógicas que hacen posible "el momento de institución de los derechos". Se trataría aquí de poder ver cómo ciertos gobiernos pueden apropiarse de las demandas populares y reintroducirlas en la gramática institucional-estatal sin dejar de lado la dimensión conflictiva de la política. Esta rearticulación de las demandas en el Estado sin perder el aliento antagónico de la política se puede ver, siguiendo a los autores, en la creación de la ley de Asignación Universal por Hijo en Argentina.

El momento privilegiado del análisis será el momento intermedio entre la demanda y la ley, ya que este permite poner en evidencia las tensiones de los diversos actores: tanto los que se encuentran a favor, como los que están en contra y los que asumen una posición crítica a la implementación de la ley.

En 2009, Cristina Fernández emite un decreto que pretende una reparación social a los ciudadanos argentinos golpeados por las políticas de liberalización económica pasadas. Este decreto de Asignación Universal por Hijo encuentra también en el camino tanto opositores dentro de los partidos contrarios a las políticas heterodoxas de Cristina Fernández, como apoyos, como la Central de Trabajadores de la Argentina y la Confederación General de Trabajo.

Este decreto se expresará como parte de un conflicto entre los de arriba o el sector empresarial beneficiado por las políticas económicas de liberalización del mercado, y los de abajo, es decir, los agentes precarizados por las medidas neoliberales. Así, este decreto es expresión de un conflicto político que tiene como actores fundamentales los 
sectores populares: "Por tanto, no se trataría de una retórica meramente técnica que buscase simplemente otorgarle mayor eficacia institucional a un Estado, sino que trata de visibilizar su dimensión politizadora" (2020: 13). La Asignación Universal por Hijo cobrará aún mayor "espesor institucional" cuando se convierta en ley y sea aprobado el proyecto por las dos cámaras legislativas. Esta ley, siguiendo a los autores, expresaría tensiones en diversas dimensiones: en tanto pone en cuestión un modelo de desarrollo de corte neoliberal, pero también entre un cierto desfase entre el aliento universal y las limitaciones materiales. Cabe resaltar aquí que la institucionalización de la demanda popular por medio de la ley no abandona su carácter conflictual, sino que esta es una ley principalmente política que pretende cuestionar un orden social pretendidamente natural. Si bien este derecho social se materializa en gran medida a partir de una infraestructura público estatal que garantiza ciertas condiciones materiales, no podemos olvidar que el movimiento piquetero de mediados y finales de 1990 fue una de las primeras expresiones de organización popular que cuestionó las formas excluyentes en las que el neoliberalismo argentino se expresaba. Se está frente a una estrategia de lo popular que en gran medida tiene como cauce la reinstitucionalización del gobierno; por ello, el Estado se manifiesta mediante sus decretos y leyes como dispositivos que responden a las demandas populares. Esta estrategia de lo popular no pone el acento tanto en el autogobierno local, sino que se plantea una cierta universalización a partir de la reapropiación política y popular de las instituciones estatales. Acaso aquí se podría evidenciar una relación más estrecha entre el movimiento popular y el Estado.

Por último, cabe mencionar que el reto pendiente para una democracia contemporánea podría ser la relación de estas dos estrategias de lo popular en clave política. La estrategia ranceriana podría brindar un mayor espesor de participación política local a partir de nuevas mediaciones, más allá de las tradicionales: partidos, sindicatos, etc. Sin embargo, la estrategia laclausiana republicana podría brindar la posibilidad de reconfigurar espacios más generales, como los referidos al Estado. Esto no significa agotar las dinámicas de cada lógica, sino comprender sus tensiones, pero también sus posibles sinergias. 


\section{Bibliografía}

Aronskind, Ricardo (2017) “Trump: ¿Un parche nacionalista a la crisis de la globalización?”. Revista Estado y Politicas Públicas, 8, pp. 59-79.

Bravo, Yacotzin (2019) El derecho como campo de disputa dentro de la geografía capitalista del despojo y la explotación. En: M. Benente y N. Navas (comp.), Derecho, conflicto social y emancipación. Entre la depresión y la esperanza. Ciudad Autónoma de Buenos Aires: CLACSO. pp. 57-74.

Delamata, Gabriela (2014) "Contestación social y acción legal. La (otra) disputa por los derechos”. Revista Sudamérica, 3, pp. 101118.

Laclau Ernesto (1996) Emancipación y diferencia. Buenos Aires: Ariel. (2000) Nuevas reflexiones sobre la revolución de nuestro tiempo. Buenos Aires: Ediciones Nueva Visión.

(2006a) La Razón Populista. Buenos Aires: Fondo de Cultura Económica.

(2006b) "Por qué construir un pueblo es la tarea principal de la política radical”. Cuadernos del Cendes, 62, pp. $1-36$.

Quintana, Laura (2012) "Singularización política (Arendt) o subjetivación ética (Foucault): dos formas de interrupción frente a la administración de la vida”. Revista de Estudios Sociales, 43, pp. 50-62.

- (2015) “ ¿Un derecho que no es un derecho? El derecho como estructura política del desacuerdo”. Revista CienciaPolítica; 10, pp. 69-63.

(2018). "Más allá de algunos lugares comunes: Repensar la potencia política del pensamiento de Jacques Rancière". Isegoría. Revista de Filosofía Moral y Politica, 59, pp. 447-448. 
(2020). Politica de los cuerpos: Jacques Rancière y las torsiones de la emancipación. Barcelona: Herder.

Rinesi, Eduardo (2019). Populismo, democracia, república (notas sobre libertades y derechos). En Cadahia, L., Coronel, V. y F. Ramirez (comp.). A contracorriente. Materiales para una teoría renovada del populismo. Bogotá: Editorial Pontificia Universidad Javeriana. pp. 3-20.

Cadahia, L., Guanche, C., Coronel, V. y S. Stoessel (2020). "Hacia una nueva lógica del populismo: de la ruptura de las instituciones a la institucionalidad populista”. Recerca. Revista de Pensament $i$ Análisi, 25(1), pp. 1-20. Publicación en prensa.

Rancière, Jacques (2006a). El odio a la democracia. Buenos Aires: Amorrortu.

Chile: LOM.

(2006b). Politica, policía, democracia. Santiago de (2012). El desacuerdo. Politica y filosofía. Buenos Aires: Ediciones Nueva Visión.

(2013). "In What Time do We Live". Politica Común, 4, pp. 1-10.

(2014). El reparto de lo sensible. Estética y politica. Buenos Aires: Prometeo. 